\title{
Reliability modelling for maintenance scheduling of mobile mining equipment
}

\author{
Raymond Summit ${ }^{1} \quad$ David Halomoan ${ }^{2}$
}

(Received 21 December 2013; revised 26 June 2015)

\begin{abstract}
It was observed that in a particular open-pit mine, failure of the front and rear suspensions of a particular model of dump truck frequently occurs before the scheduled replacement of the parts. The Weibull distribution is used to model the time to failure of these components. Maximum likelihood estimators of the parameters are obtained and used to find a more appropriate replacement time.
\end{abstract}

\section{Contents}

\section{Introduction}

http://journal.austms.org.au/ojs/index.php/ANZIAMJ/article/view/7863 gives this article, (C) Austral. Mathematical Soc. 2015. Published July 23, 2015, as part of the Proceedings of the 11th Biennial Engineering Mathematics and Applications Conference. ISSN 1446-8735. (Print two pages per sheet of paper.) Copies of this article must not be made otherwise available on the internet; instead link directly to this URL for this article. 
2 Method

C529

2.1 Pareto analysis . . . . . . . . . . . . . . . . . C529

2.2 Modelling assumptions . . . . . . . . . . . . . . . C530

2.3 Reliability modelling . . . . . . . . . . . . . . C532

3 Results and discussion

C534

4 Conclusions and recommendations

C538

References

C540

\section{Introduction}

Maintenance costs in the mining industry are significant. Faitakis et al. [2] reported that about 5\% of mining production in North America is lost in unscheduled downtime. Downtime causes valuable resources, both equipment and human, to remain idle rather than be engaged in productive endeavours. Clearly, reducing downtime is a worthwhile aim of any mining venture. However, this needs to be tempered with the cost of scheduled maintenance, including the cost associated with scheduled downtime [4]. Costs associated with scheduled and unscheduled maintenance are the subject of many studies [1, e.g.].

Maintenance is either preventive or corrective. Preventive maintenance is planned and carried out at predetermined intervals. The aim of scheduled maintenance is to reduce the probability of equipment failure, thus maximising equipment availability. Preventive maintenance is further subdivided into condition based maintenance and predetermined maintenance. In condition based maintenance, regular inspection and performance monitoring are conducted to ensure that maintenance is performed before failure occurs. On the other hand, predetermined maintenance is carried out at established usage intervals and is based on the assumption that similar machines will display 


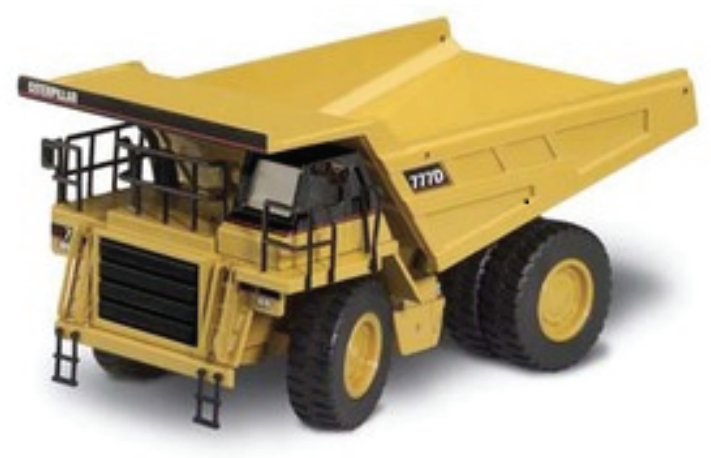

Figure 1: Caterpillar 777D.

similar failure behaviour. Conversely, corrective maintenance is conducted urgently when needed, without planning. Although performing maintenance only if and when needed may reduce maintenance costs, it does result in unplanned downtime and production loss, which then increases production costs. Thus it is desirable to keep corrective maintenance to a minimum.

This study investigates the suitability of the scheduled maintenance program at a mine site. For propriety reasons, the site location and the company running the operations cannot be disclosed. The purpose of this article is to evaluate the current scheduled maintenance program at the site. To do so for the entire fleet of mobile equipment, or even for all components of a particular model of equipment, is beyond the scope of this study. However, the techniques developed herein can be extended to cover as many components and items of equipment as is necessary.

The open cut coal mine used in this study is serviced by a fleet of two types of dump trucks and various shovels. We analyse the maintenance schedule of the Caterpillar 777D, shown in Figure 1, because there are twenty in use at the site, the most common mobile equipment in the fleet. The Caterpillar 777D is a widely-used dump truck in the mining industry throughout the world. Its generous 91 tonne payload makes it ideal for moving coal, ore and overburden 
in open pit mines.

Our investigation starts with a Pareto analysis to find the most troublesome component on the Caterpillar 777D. We model the failure of this component and use the model to judge the adequacy of the current maintenance schedule. Finally, we compare the reliability of the same component on another fleet of Caterpillar 777D trucks at a different site.

\section{Method}

\subsection{Pareto analysis}

The Caterpillar 777D contains a large number of components, any of which may fail during operation. A component replacement database is maintained, which details when components were replaced. Figure 2 presents a frequency chart of the number of component replacements over a period of five years at our mine site. Examination of the chart reveals that the most frequently failing component is a suspension. In addition, the chart lists suspension components as four entries, corresponding to the four positions: left rear (LR), left front $(\mathrm{LF})$, right rear $(\mathrm{RR})$ and right front $(\mathrm{RF})$. The operational maintenance schedule at the mine calls for the replacement of front and rear suspensions at different intervals, namely 12000 and 9000 engine hours, respectively. As such, we model the failure of front and rear suspensions separately in this study.

We now analyse the failure modes of the suspension components. Figure 3 indicates the reasons for component replacements and reveals that the majority of replacements are unplanned, leading to unscheduled downtime and production loss. Of the failure modes identified, seal failure is the most frequent. Load friction can cause suspensions to deteriorate, leading to a leak in the component. Figure 4 provides an example of seal failure. We proceed by modelling the failure of suspensions due to this one failure mode, 


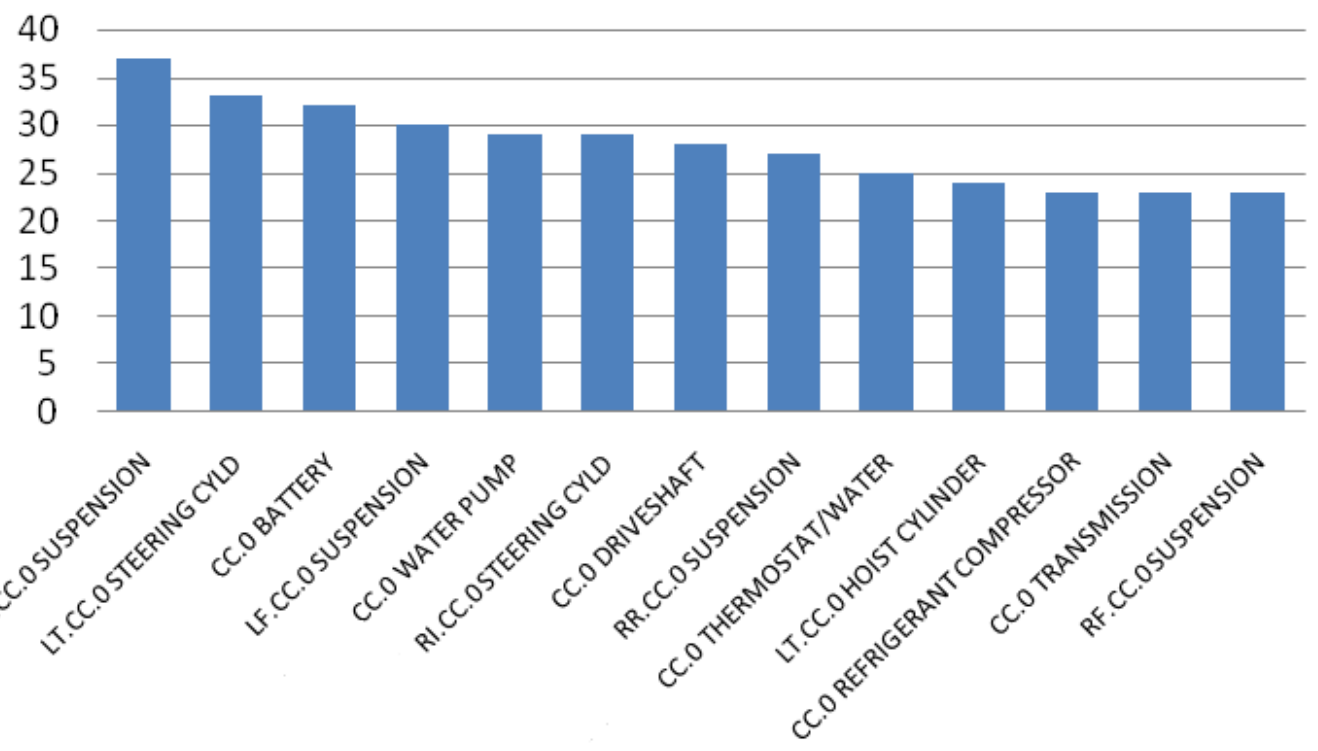

Figure 2: Component failure frequency.

in preference to modelling all failures using a multi-modal distribution, as that leads to an overly complex model.

\subsection{Modelling assumptions}

Standard modelling assumptions are made in our analysis. These are:

- failure times of the component are independent and identically distributed;

- all repairs are as good as new, since failed components are replaced by new ones;

- there are no significant delays in reporting failures. 


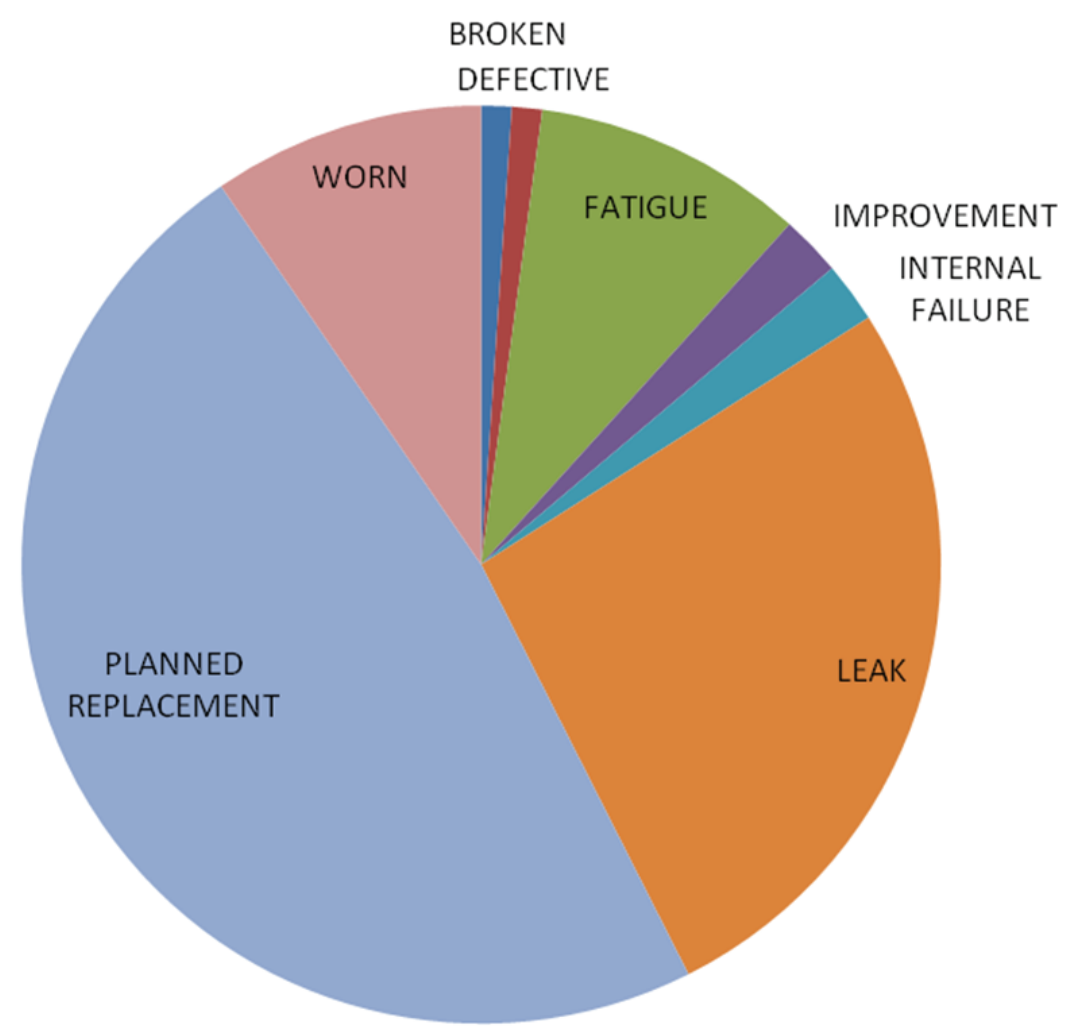

Figure 3: Failure modes.

To validate the assumption that component failures are independent, a serial correlation test is conducted. Figure 5 displays the time between failure (TBF) of sequential failures using: (a) front suspension data and (b) rear suspension data. Neither plot displays any trends, indicating that the TBF of components in each location are not influenced by their previous TBF. This evidence supports the assumption of independent failures. 


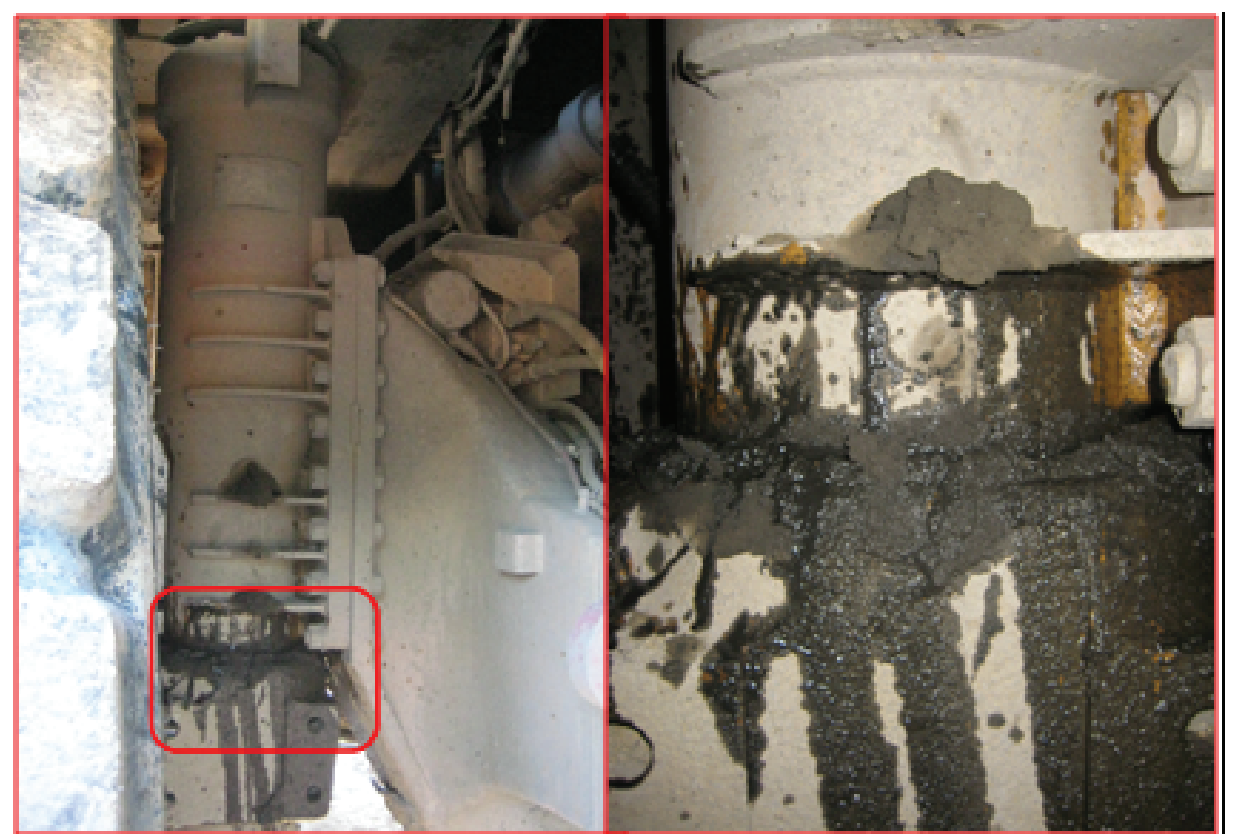

Figure 4: Seal failure.

\subsection{Reliability modelling}

Because of its flexibility, the two-parameter Weibull distribution is widely used to model failure times of mechanical systems [3]. However, the log-normal and exponential distributions are also used to model failure times [1]. Our analysis commences by investigating the suitability of each of these three distributions for both the front and rear failure data. Maximum likelihood is used to fit the three models against the empirical data, which comprises 30 failed and 29 right-censored components in the front position, and 60 failed and 34 right-censored components in the rear position. Figures 6 and 7 display the model fits, together with their $90 \%$ confidence intervals (CI), and clearly show the inadequacy of the exponential model. Both the Weibull and log-normal models fit the data reasonably well, with the Weibull offering a slightly better 


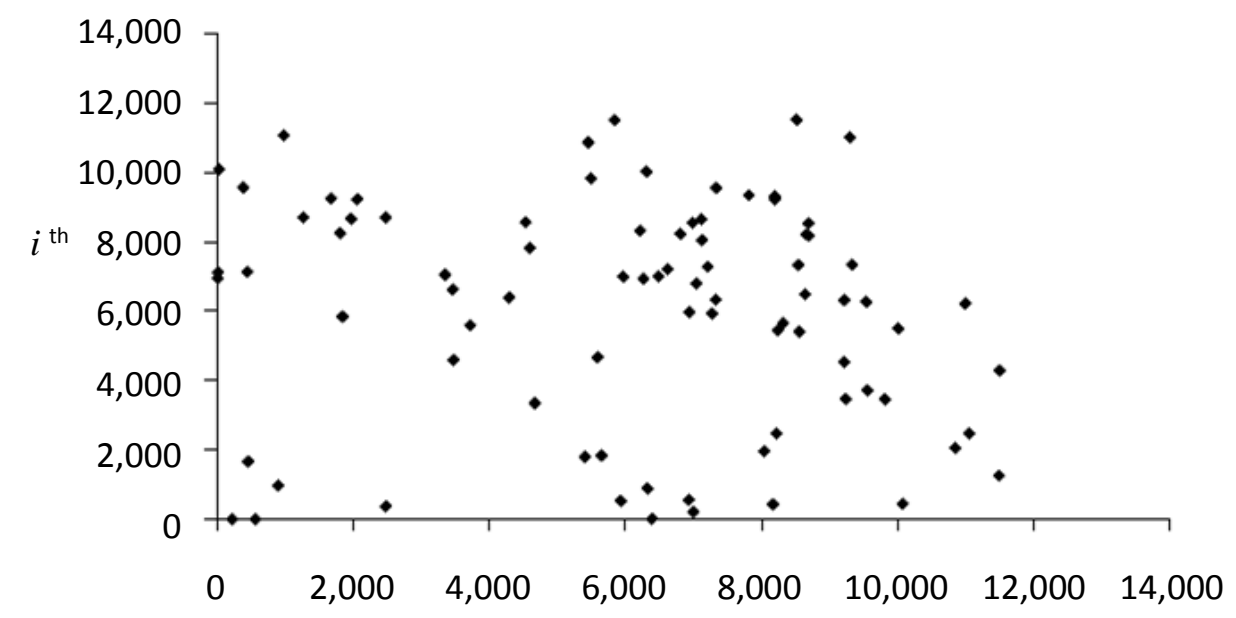

(a)

$(i-1)^{\text {th }}$

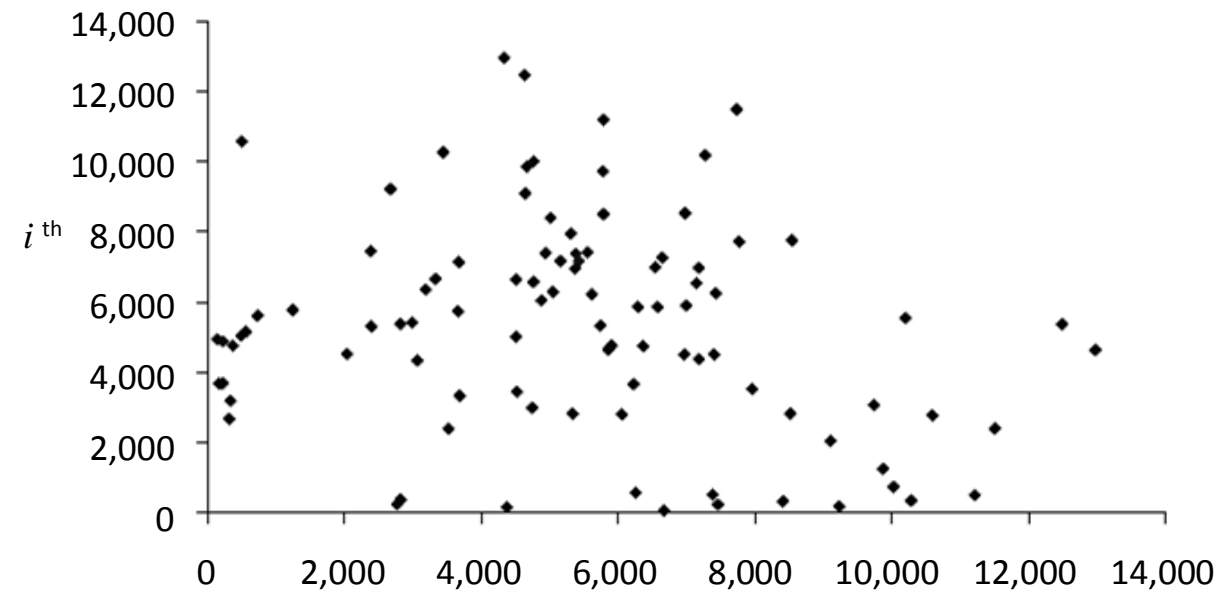

(b) $(i-1)^{\text {th }}$

Figure 5: Sequential TBF plot: (a) front and (b) rear suspension data. 
Table 1: Likelihood values for Weibull and log-normal models.

\begin{tabular}{l|cc} 
& Weibull & Log-normal \\
\hline Front & -272.7 & -273.7 \\
Rear & -570.9 & -576.3
\end{tabular}

visual fit. Scrutiny of the maximum likelihood values presented in Table 1 reveals that they are slightly higher for the Weibull distribution. Therefore, for both data sets, we proceed by modelling failure times $t$ using the Weibull distribution,

$$
f(t)=\frac{\beta}{\eta}\left(\frac{t}{\eta}\right)^{\beta-1} \exp \left[-\left(\frac{t}{\eta}\right)^{\beta}\right],
$$

where $\beta$ is the shape parameter and $\eta$ is the scale parameter.

\section{Results and discussion}

On selecting the Weibull distribution to model failure times, the next step is to obtain parameter estimates. These are shown for our coal site in the first data row of Table 2, which also displays the mean time to failure (MTTF) and their $90 \%$ CI. The MTTF for both front and rear suspension are significantly less than the scheduled replacement times of 12000 (front) and 9000 (rear) engine hours - a clear indication that the scheduled times are not appropriate in this situation.

Figure 8 illustrates why different parameters are required to model failure times of front and rear suspensions. Front suspensions have a longer expected life than rear suspensions, which is consistent with their higher MTTF and longer scheduled maintenance intervals. Figure 8 also shows that the front suspension data have less spread than the rear suspension data.

Because the manufacturer's recommended maintenance schedule does not adequately match the observed failure patterns at our coal site, further data 


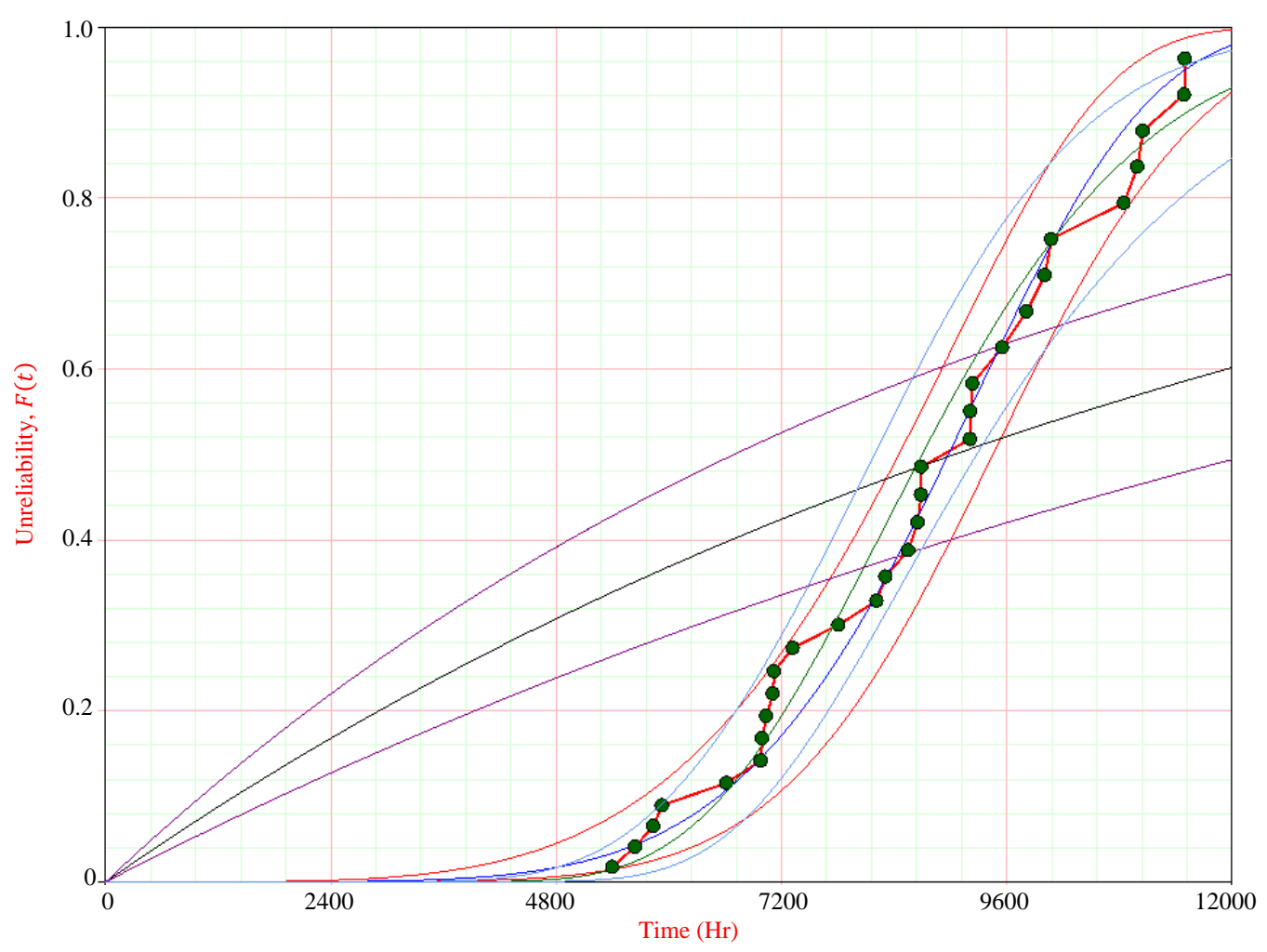

Figure 6: Cumulative failure of front suspensions (dots) and fitted models with $90 \%$ confidence interval: Weibull (blue/red), log-normal (green/blue) and exponential (black/magenta).

\begin{tabular}{l|l|rr|rr} 
& \multicolumn{2}{c}{ Table 2: Parameter and MTTF estimates. } \\
Site & Position & \multicolumn{2}{|c}{ Parameter } & \multicolumn{2}{c}{ MTTF } \\
& & $\beta$ & $\eta$ & Mean Life & $90 \%$ CI \\
\hline Coal & Front & 5.915 & 9552 & 8855 & {$[8376,9362]$} \\
& Rear & 2.655 & 7768 & 6904 & {$[6345,7514]$} \\
\hline Metal & Front & 18.24 & 18730 & 18190 & {$[17890,18498]$} \\
& Rear & 4.04 & 13130 & 11910 & {$[11290,12560]$}
\end{tabular}




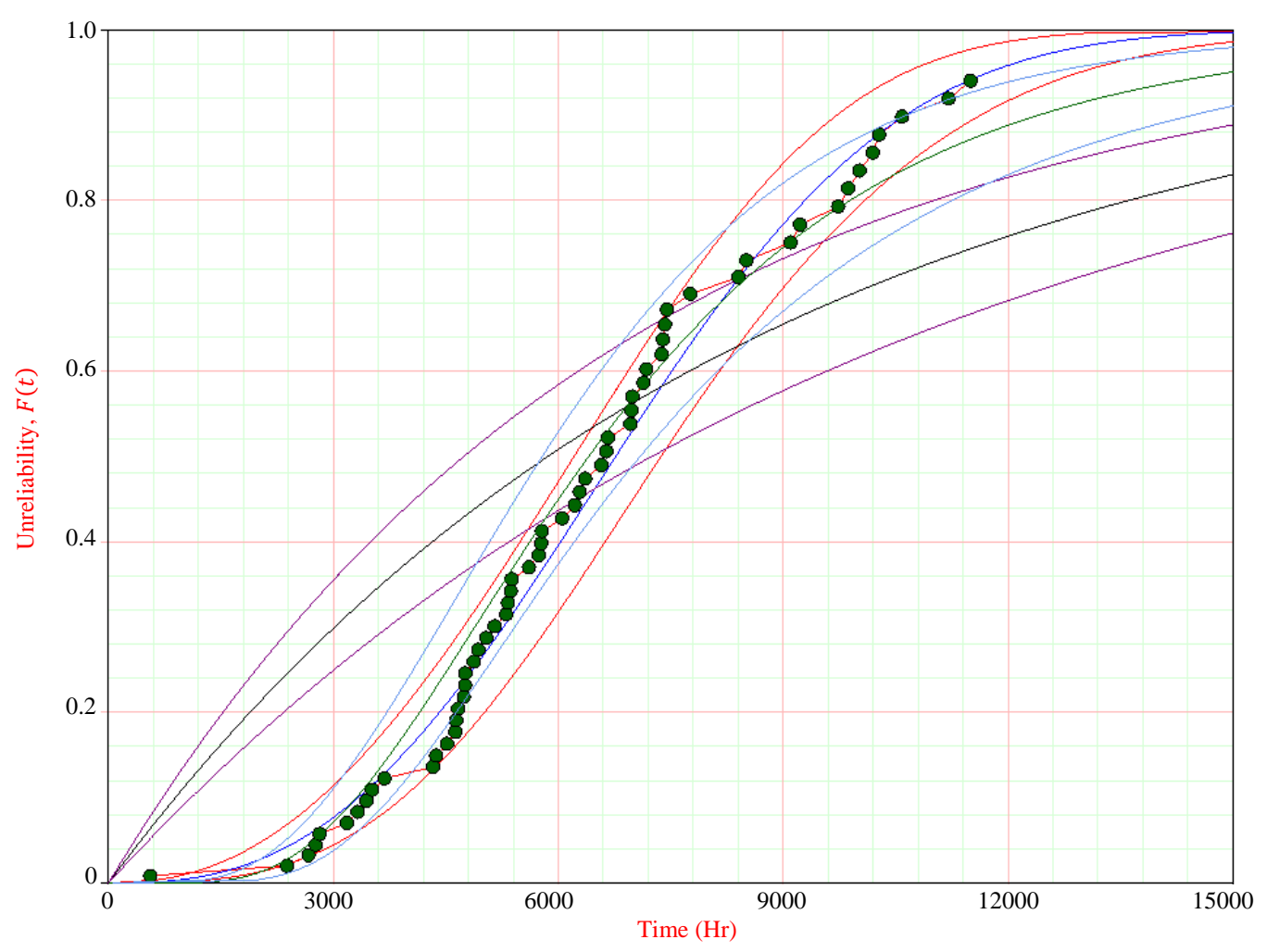

Figure 7: Cumulative failure of rear suspensions (dots) and fitted models with $90 \%$ confidence interval: Weibull (blue/red), log-normal (green/blue) and exponential (black/magenta). 


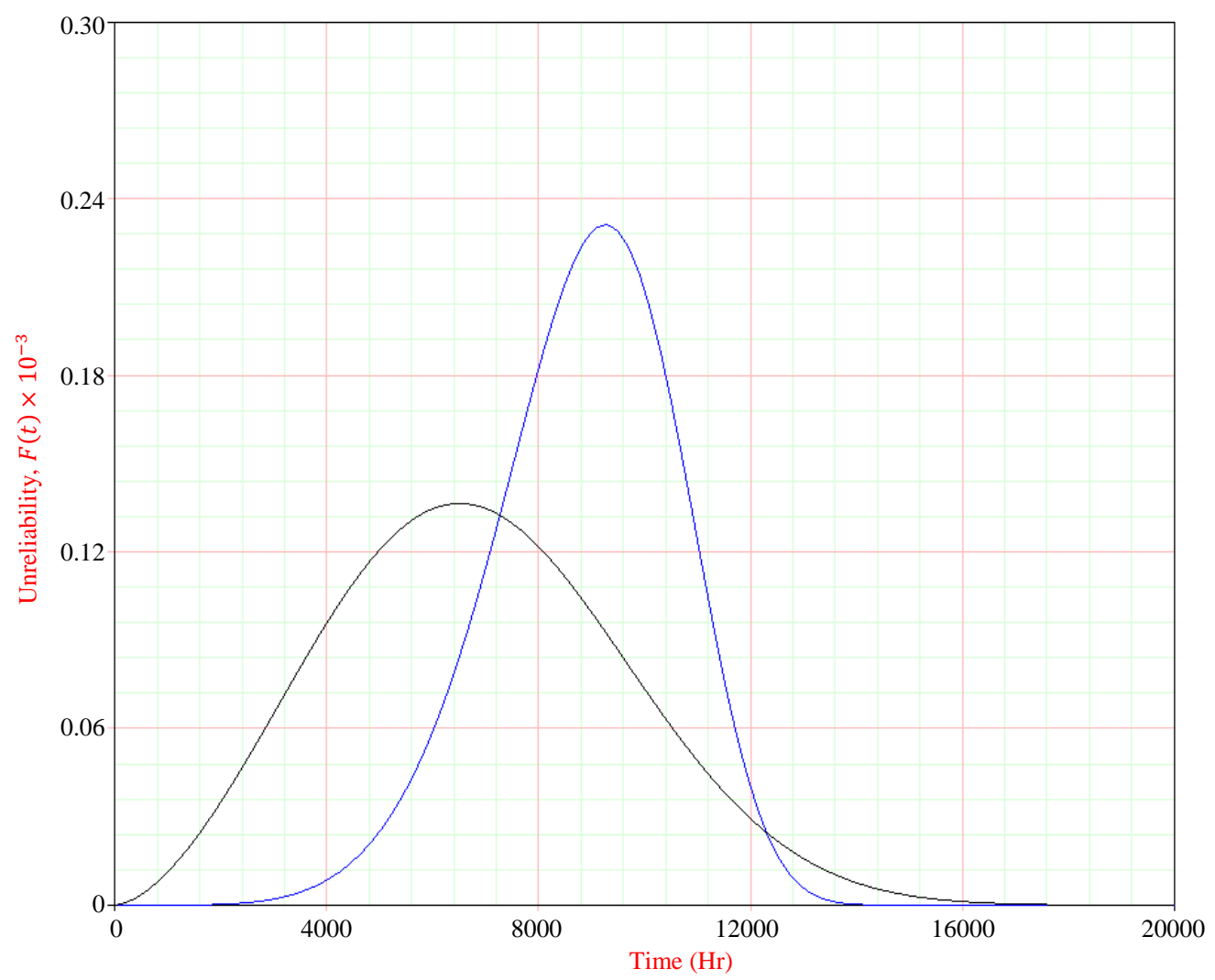

Figure 8: Weibull failure distribution of front (blue) and rear (black) suspensions. 
from a comparable site are obtained as a means of benchmarking. We again collect data for suspension failure on the Caterpillar 777D dump truck, this time at a metal mine site. These data are taken for a sample of 44 front and 82 rear suspensions. Weibull models are generated from the data and compared to the model for the original coal site. The parameter estimates, MTTF and their $90 \%$ CI for this metal mine site are shown in the second data row of Table 2.

Given the confidence intervals in Table 2, it is clear the MTTF at the coal site is much less than the MTTF at the metal site for both front and rear suspensions. A number of factors affect the MTTF of suspensions, including the material being mined, haulage road conditions, weather conditions and truck specifications. The mine site in our main study is an open-pit coal mine, which is likely to experience dustier conditions than the metal ore mine site. Dusty conditions cause greater wear on suspension components as a result of dust and dirt working their way around the seal. In addition, the trucks at each of the two sites were manufactured in different countries, which may also be a contributing factor to the variation in failure distributions of the suspensions.

\section{Conclusions and recommendations}

Our analysis shows that the scheduled replacement of front and rear suspensions at 12000 and 9000 engine hours, respectively, leads to much corrective maintenance. This causes unscheduled downtime, which results in lost productivity. Thus revision of these scheduled maintenance intervals is in order.

The $90 \%$ CI for the probability that the front and rear suspensions survive to scheduled maintenance are $2-8 \%$ and $16-30 \%$, respectively. These probabilities clearly indicate that the current scheduled replacement intervals are too long in this particular mine. Decreasing the maintenance interval would result in a reduction of unscheduled downtime, which would in turn help 
reduce production costs.

At the mine site, the $90 \%$ CI for scheduled replacement of the front and rear suspension units are [5882, 7248$]$ and [2 822, 3329] engine hours, respectively. This is based on the achievement of $90 \%$ survival to the scheduled replacement time. The current scheduled replacements of front and rear suspensions occur at 12000 and 9000 engine hours, respectively, which fall well outside the above confidence intervals.

Poor haulage road conditions may be a contributing factor to the low life expectancy of the suspensions at our mine site. Thus it may be beneficial to the company to improve haulage road conditions, as this may reduce maintenance costs. Other dust minimisation efforts may also bring similar benefits. Experimentation is needed in this area and a cost analysis should be conducted in order to determine if any cost benefits can be achieved.

The assumption that failure times of suspensions are independent and identically distributed should be further tested. It is plausible that failure of other components may affect failure of suspensions. Although beyond the scope of the present study, further investigation should be conducted into any correlation between failure of components.

Further analyses, similar to the one discussed in this article, need to be conducted on other components so that optimal scheduled replacement intervals for these other components can be determined. Again, experimentation on mine conditions could be conducted to determine any benefits that may be garnered in terms of the maintenance of other components. Once optimal scheduled maintenance intervals for individual components are determined, an overall maintenance schedule for the trucks can be compiled that takes into consideration each component's life expectancy and the downtime associated with both scheduled and unscheduled maintenance.

Acknowledgements We greatly appreciate the reviewers' comments as their valuable suggestions have helped improve this article. 


\section{References}

[1] E.A. Elsayed. Reliability Engineering. Hoboken: Wiley, 2012. http:// au.wiley.com/WileyCDA/WileyTitle/productCd-1118137191.html C527, C532

[2] Y. Faitakis, C. Mackenzie and G. J. Powley. Reducing maintenance costs through predictive fault detection. CIM Bull., 97(1076), 2004. http://www.cim.org/en/Publications-and-Technical-Resources/ Publications/Technical_Papers/2004/1/BULL-2004-01-03 C527

[3] D. N. P. Murthy, M. Bulmer and J. A. Eccleston. Weibull model selection for reliability modelling. Reliab. Eng. Syst. Safe., 86(3):257-267, 2004. doi:10.1016/j.ress.2004.01.014 C532

[4] H. Shore. Optimum schedule for preventive maintenance: a general solution for a partially specified time-to-failure distribution. Prod. Oper. Manag., 5(2):148-162, 1996. doi:10.1111/j.1937-5956.1996.tb00391.x C527

\section{Author addresses}

1. Raymond Summit, WA School of Mines, Curtin University of Technology, Western Australia, Australia.

mailto:rsummit@usc.edu . au

2. David Halomoan, WA School of Mines, Curtin University of Technology, Western Australia, Australia. 